Supplement of Nat. Hazards Earth Syst. Sci., 16, 2137-2144, 2016

http://www.nat-hazards-earth-syst-sci.net/16/2137/2016/

doi:10.5194/nhess-16-2137-2016-supplement

(c) Author(s) 2016. CC Attribution 3.0 License.

(c) (1)

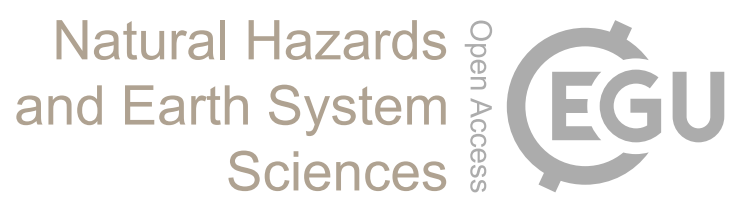

Supplement of

\title{
InSAR observations of the 2009 Racha earthquake, Georgia
}

Elena Nikolaeva and Thomas R. Walter

Correspondence to: Elena Nikolaeva (elenanikolaeva@ hotmail.com)

The copyright of individual parts of the supplement might differ from the CC-BY 3.0 licence. 
Supplement Figure S1. Example of the 20090904-20091020 interferogram processing stages: (a) filtered interferogram, (b) unwrapped interferogram, (c) interferogram after orbit correction, (d) Interferogram after topography correlated atmospheric delay. (a), (b), (c) in the satellite azimuthrange coordinates; (d) in the ground coordinates (UTM). The deformation signal is within the white circle.

(a)
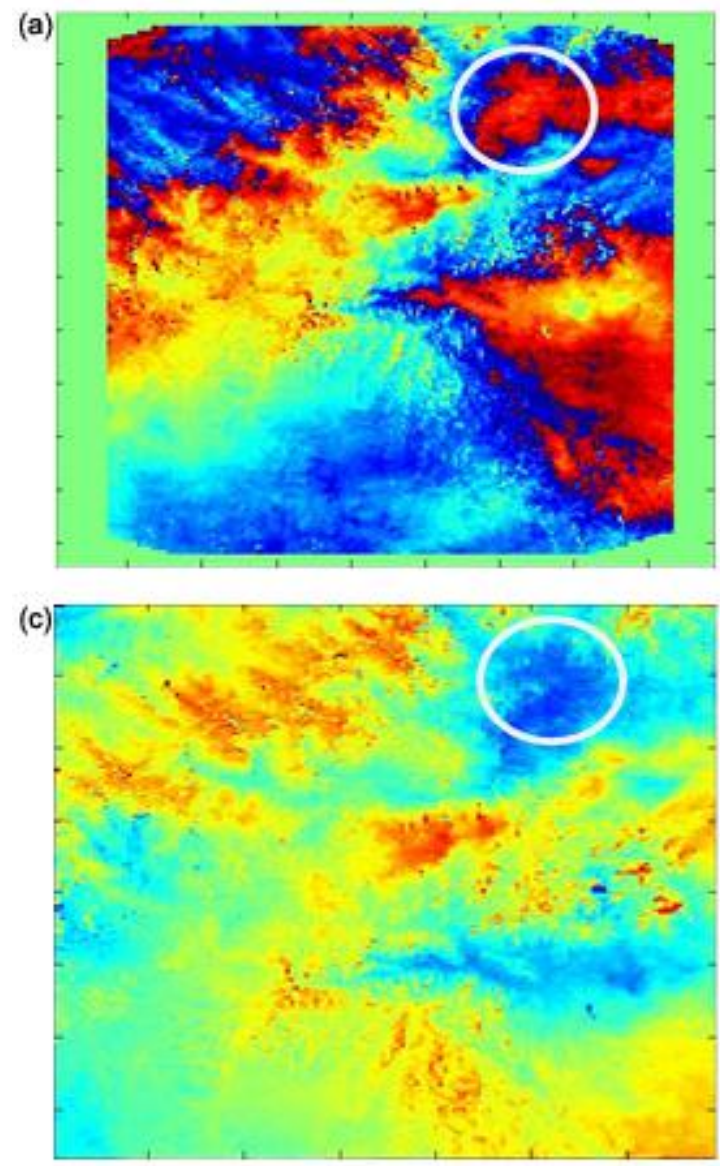

(b)
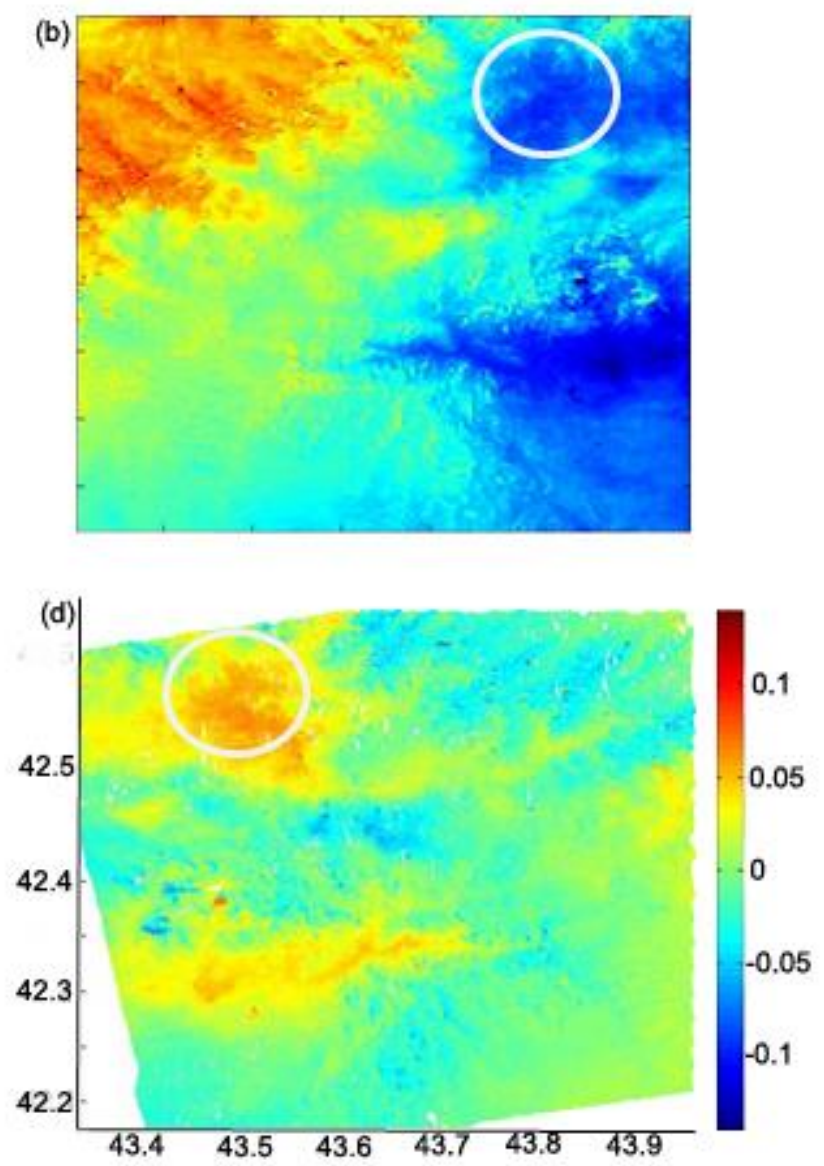